\title{
Foreshadowing Contemporary Digital Cartography \\ A Historical Review of Cinematic Maps in Films
}

\author{
Sébastien Caquard \\ Département de Géographie \\ Université de Montréal
}

\begin{abstract}
Through an historical review of cinematic maps - or "cinemaps" - this paper argues that contemporary digital cartography was conceptualized in films. This argument is first developed through a discussion of the emergence of animated maps in docudramas of the 1910s. These early cinemaps were followed by more sophisticated examples that foreshadowed the structure and design principles of "modern" cartography. The cinemap that appears in the movie $M$ (Fritz Lang 1931) can be considered the first "modern" map as it prefigures many of the current functions of contemporary digital cartography such as the combination image/map, use of sound, shifts in perspective, and spatial analysis. The remaining functions of digital cartography, including zooming and live data rendering were conceptualized in cinema by the 1960s, as illustrated by examples from movies such as Casablanca, Dr. Strangelove and Goldfinger. When professional cartographers were creating their first animated maps, most of the functions of contemporary digital cartography had already been implemented in cinema. Building on these results, the paper anticipates the future incursion of mapping technologies into interpersonal, confidential, and private spaces through the study of contemporary cinemaps.
\end{abstract}

\section{Key Words}

Cinematic Maps, Digital Cartography, Virtual Globes, Cinema 


\section{Introduction}

On a virtual globe anybody can easily zoom in and out to different places, fly through landscapes, navigate above and inside cities, find the shortest path between places, measure distances, contribute comments, visualize all kinds of data, listen to audio documents, and watch videos. These different functions synthesize the potential of contemporary digital cartography: Interactivity, animation, multimedia, spatial analysis, perspective changes, zooming capabilities, live data rendering, and pervasiveness. It has been argued that these functions are rooted both in cartography and in GIScience. Indeed, the technological developments that emerged in the 1950s and 1960s that have shaped the discipline of GIScience have been influenced by a century of hand-drawn map overlay techniques and cartographic analysis (Mark et al. 1996; Foresman 1998). However, the origins of contemporary digital cartography are much more complex and rhizomatic. They cross and connect multiple fields, domains, and disciplines. Indeed, many of the important landmark maps in history have been created outside the field of cartography. Those maps were designed by engineers, military officers, artists, and sometimes by filmmakers.

This paper explores the world of cinematic maps - or "cinemaps," which can be defined as maps in motion developed specifically in cinema for narrative purposes - with the aim of reviewing landmark examples from different periods in film history. The overall goal of this review is to understand how these early cinemaps resonate with contemporary digital cartography. In the first section, the characteristics and functions of very early cinemaps created for docudramas in the 1910s and 1920s are introduced and discussed. The second section focuses on a very specific cinemap that appears in the movie $M$ (Fritz Lang, 1931), which embodies many of the characteristics of contemporary digital cartography. The third section identifies more modern cinemaps that showcase other significant functions of digital cartography. Finally, building on these results, the last section anticipates future developments of cartography based on the study of contemporary cinemaps. This paper concludes by arguing for a closer look at cinema as a conceptual and technical source of inspiration for professional cartographers.

\section{Pre-1931: Early cinemaps in docudramas}

Animated maps appeared in motion pictures long before they emerged from cartographers' laboratories. While the interest in using film in cartography is rooted in the propaganda of WWII (Speier 1941), it is in the 1950s, with the work of pioneers such as Norman Thrower (1959), that professional cartographers began developing animated maps. At that time, cinematic maps were already common in feature films. As Mark Harrower (2004, 37) points out, "in the 1930s and 1940s, movie theaters were the only place to watch animated maps." Animated maps can be traced to an even earlier period as illustrated by the rotating earth in the movie The Flying House (Winsor McCay, 1921) described by Jeremy Crampton $(2003,38)$. There is even some evidence that animated maps appeared in cinema as early as the $1910 \mathrm{~s}^{1}$.

One of the first cinemaps ever created was for a 1918 docudrama entitled Among the Cannibal Isles of the South Pacific (Martin E. Johnson, 1918). An animated black line traces the journey of director Martin Johnson and his wife Osa from the New Hebrides Islands to the Solomon Islands in the South pacific (figure 1). While the film purports to offer the first footage of these exotic communities, it contributes to the construction of geospatial archives of the time, which was one of the goals of early cinema (see Castro 2006). The Johnsons develop the narrative through the increasing danger they face by traveling through these unexplored communities. As a result, the danger increases as they travel to more and more remote locations. Footage of the Johnsons dancing at the beginning of the movie is juxtaposed with a dramatic escape from cannibals at the end. In this sense, the audience is never conscious of where reality ends and where fiction begins.

\footnotetext{
${ }^{1}$ As there is no offical record of the presence of cinemaps in movies, and as early films are not easily accessible, it is obviously impossible to provide a comprehensive list of cinemaps. It would be presumptuous to pretend that the examples of cinemaps presented in this paper are systematically the earlier ones for each cartographic function described. The examples used reflect the personal experience of the author through more than a decade of collecting cinemaps.
} 


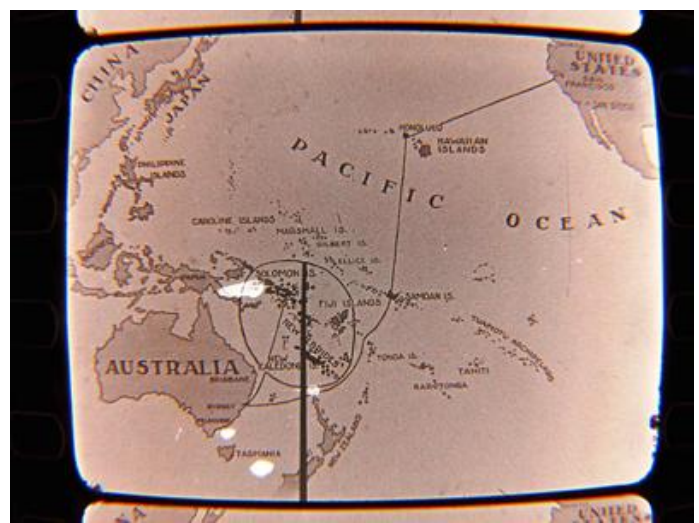

Figure 1. Screen capture of one of the earliest cinemaps from the movie Among the Cannibal Isles of the South Pacific (Martin E. Johnson, 1918) (can 236H - Courtesy The Library of Congress NAVCC).

The unfolding map that shows the trip from the New Hebrides to the Solomon Islands plays on this duality. On the one hand it reinforces the veracity of documentary discourse by grounding it in existing places and establishing what Tom Conley $(2006,4)$ calls "a fallacious authenticity of a place." On the other hand, the animated map also contributes to the narration as it increases the dramatic tension of the film. Indeed, the tension rises as both characters travel between the welcoming communities of the New Hebrides to the dangerous and savage communities of the Solomon Islands. The duality of the map as an historical record and narrative device characterizes the ambivalence of this docudrama. The map also plays a structural role as it appears at the turning point of the film; it links the first part of the film describing the "good" savages of the New Hebrides to the second part of the film depicting the "barbaric cannibals" from the Solomon Islands. This cinemap serves as a transition - a cartographic intertitle ${ }^{2}$ - between the close and the remote islands, the "good" and the "bad" savages.

This map also contributes to the dissemination of an imperialist discourse that is associated with the institutional configuration of cinema at the beginning of the twentieth century (Shohat and Stam 1994). Indeed, it blends real geographical places with fictional perspectives developed for and by a Western audience. As a result, the image of the Solomon Islands is associated with cannibalistic and savage imagery. As with conventional maps, early cinemaps contributed to the creation of a cultural construction of territorial perspectives.

In 1923 another docudrama entitled Le Tour de la France par Deux Enfants (Louis de Carbonnat, 1923) was released, which included a series of cinemaps. In a sense, this film can be considered "the prototype of the road movie" (Hayward, 2005: 112). It is based on the eponymous pedagogical book published in 1877 by Mme Augustine Fouillée under the pseudonym of G. Bruno. This book was written in the context of the French defeat in the 1871 war against Germany. The book was a commercial success with hundreds of reprints and millions of copies sold (Saustier 2006). This commercial success had a social impact as the book was used as a school textbook in France for decades. The book presents the peregrinations of two orphans, Julien and André (7 and 14) who are leaving the Lorraine region in the East of France, newly annexed by Germany, to find their uncle in Marseille in order to keep their French nationality. During this journey, the two boys travel through France, which emphasizes "the most noble side of the patria" as well as the importance of "the honor, the work, and the deep respect of duty and justice" (Bruno 1877, 4) (author's translation). The book and the film became the pretext for teaching and celebrating France's national diversity and achievements.

In the book, this celebration was supported by a series of maps, which inspired the cinemaps that were later incorporated into the film version. Five of the maps served as an introduction to each of the five "chapters" of the film. These cinemaps were very similar to the one created by the Johnsons: an animated black line traced on a static map of France. Nevertheless, some of them were slightly more sophisticated as they included animated

\footnotetext{
${ }^{2}$ In cinema, an intertitle is a shot inserted between two scenes that includes usually text. Intertiles were mainly used in silent movies to convey dialogue and/or narration.
} 
symbols such as a pictogram of a boat moving along the canal, recording the journey of the two heros. These cinemaps may well have provided the very first examples of animated symbols.

The function of these cinemaps were also similar to the one developed by the Johnsons. As each chapter is introduced, the narrative reinforces the veracity of the mapping discourse by linking it to actual places. Their recurrent use contributes to a confirmation of French national integrity. The cinemaps, just like the maps in the original book, show a French territory that includes Lorraine and Alsace ${ }^{3}$. In other words, they participate in the construction of a nationalistic discourse in both the book and the film.

As illustrated by these two examples, early cinemaps reveal different functions in docudramas. They support the documentary claim of the films by linking them to real places; they reinforce the dramatic tension of the narration; and they contribute to the dissemination of a political discourse. Of special interest to cartography is the use of animation and animated symbols in maps. These examples characterize the techniques used in early cinema in which the camera is immobile and the movement is added to films (Clarke and Doel 2007). In these early cinemaps, the camera is immobile and elements are animated, a functional technique of digital cartography, which was not developed by professional cartographers until several decades later.

\section{1931: A turning point between classical and contemporary cartography}

In 1931, Austrian born director Fritz Lang, released his first synch-sound film: $M$. The film tells the story of a serial killer who preys on children in 1930s Berlin, and who is on the run from police and an organized crime syndicate. According to Lang, the film is a "narrative documentary" about a serial killer (Eibel 1988), even if it has been interpreted by some as a critique of the emergence of National Socialism in Germany (Buache 1984; Marie 1989).

The film begins with a montage sequence showing in alternating passages the mother of Elsie Beckmann waiting for her daughter, who leaves school and walks the same route as the murderer. Elsie is murdered and left in an urban wasteland. She is the eighth child to be murdered which creates terror in the streets. Tensions mount as neighbors begin to suspect one another. At the crime scene police find a paper bag filled with candy crumbs which leads the detectives to search for the store that sold the killer the candy. First, the candy shops within a radius of two kilometers of the crime scene are visited. As the search is unsuccessful, the circle is widened. This systematic process is illustrated with a cinemap (see Figure 2). This map is centered on the neighborhood where the body was found. The neighborhood is represented by a wide view of the wasteland superimposed on the map. The search process is illustrated by a compass drawing circles around the neighborhood to illustrate the widening of the search.

According to Claude Beylie (1997), in $M$, every detail is meaningful. Indeed, in what seems to be a very simple 18 second cinemap, several details link this map to classical cartography, and project it simultaneously into digital cartography.
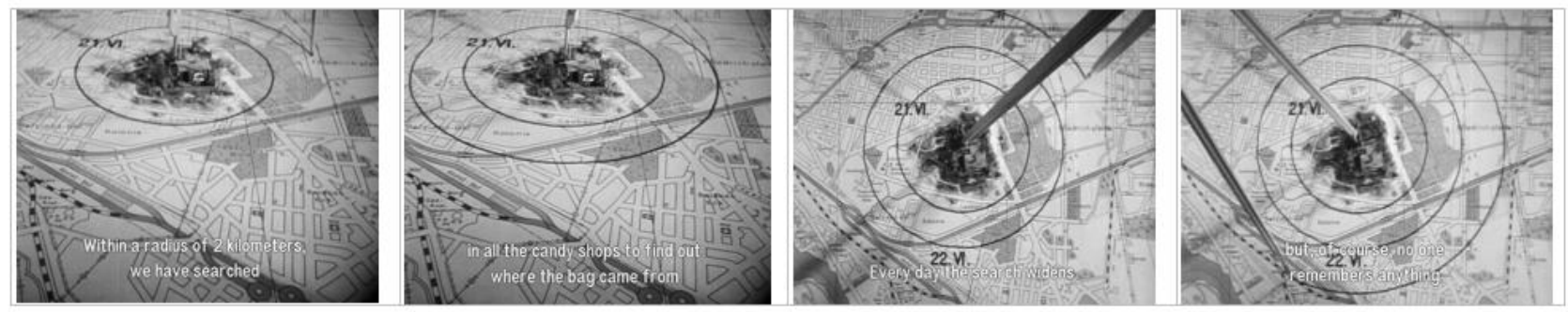

Figure 2. This cinemap from the movie M (Fritz Lang, 1931) represents a turning point in the history of cartography as it both refers to classical cartography and predates many of the future functions of digital cartography.

\footnotetext{
${ }^{3}$ It is interesting to note that these territories were German at the time the book was published (1877) and French at the time the film was released (1923), as they were annexed by France after WWI.
} 


\section{Referring to Classical Cartography}

An allusion to classical cartographic techniques is made through the use of two shots angled on the map.

These two angles refer to the two perspectives that have dominated cartography historically. The first refers to an oblique perspective, sometimes called "perspective militaire" (Buci-Glucksmann 1996) or a panoramic map. This linear perspective is based on the use of a grid to create the impression of perspective on a flat surface. It has been widely used by artists since the Middle Ages, to represent landscapes. It was also very popular in the late $19^{\text {th }}$ century in the depiction of U.S. and Canadian cities (Hébert and Dempsey, 1997). The second angle is vertical. This bird's eye view or 'God-trick' (Haraway 1990) characterizes both the more modern and scientific representation of Earth as well as the God perspective. Denis Cosgrove argues that the fifteenth-century rediscovery of this perspective in Ptolemy cartographic work "marks the beginning of European Modernity" (Cosgrove 1994, 271) (see also Pickles 2004). These two subsequents views of the same map capture the passage from a classic to a more modern perspective in cartography.

The symbolic reference to classic cartography is also made clear by the presence of the compass. Indeed, the compass symbolizes the importance of geometry in the history of cartography and its uses to explore and map the world. The compass appears in many paintings of the $17^{\text {th }}$ century including the famous "The geographer" from Vermeer (1668-1669). At the time of $M$ 's release in 1931, the compass was still a common tool used to measure distances from one point to another on a map. Nevertheless its presence on this cinemap was certainly not required as the circles could have been animated by themselves, using similar techniques as the one used in previous examples of animated maps (see section 1). The presence of the compass in the shot emphasizes the idea of a hand-drawn map, and links this cinemap to its time as this tool was probably used by the police in the 1930s. Therefore, the presence of the compass refers simultaneously to the cartographic methods used at the time of the movie as well to the past centuries of using manual methods for mapping and measuring territories.

It is also interesting to note that the hand holding the compass is never visible in the shot. In other words, the compass seems to draw the circles mechanically instead of manually. In this sense, the map is no longer totally drawn by hand. It is already automated and this alludes to a more "modern" notion of cartography. Indeed, as described by several authors, the emergence of GIS was based on the desire to automate map production (see Tobler 1970; Tomlinson 1988; Coppock 1988). In fact, "the most straightforward objective of digital technology is the emulation of manual methods, to the point where the two products are indistinguishable" (Goodchild, 1988: 317). This is precisely the "emulation" that is happening in the cinemap: it is made both manually and automatically. This is a turning point between hand-made classical cartography and machine rendered digital cartography. In a sense, this map refers to classical and historical conception of cartography while at the same time utilizing many of the characteristics of contemporary cartography.

\section{Predating Contemporary Cartography}

The $M$ cinemap predates several of the elements of contemporary digital cartography. First, it combines two kinds of images in one map: a photo real element, which represents a realistic image of the neighborhood where Elsie's body has been found, and a conventional topographic map. This combination of photographic and cartographic signs gives a very special texture to this cinemap that predates many contemporary maps in which aerial and satellite images are systematically combined and overlaid with cartographic symbols.

Secondly, this map integrates a new media: sound. The milestone in synchronized sound movies is the The Jazz Singer (Alan Crosland), released in 1927. In fact, many attempts to use sound in films were made in the 1910s and 1920s simultaneously in Europe and in the United States (Lange and Bromberg 2003), but the use of synchronized sound in cinema only became fully operational in 1928 and common by 1930 . The $M$ cinemap of 1931 may well have been the first audio-visual map ever made. The interaction between image and sound produces a new form of narration, in which the voice-over supports the cartographic narration. In this case, the voice describes the search process by the police, while near-silence increases the dramatic tension. By 1931, audiences were growing accustomed to "talking" movies, but the quasi-absence of music (except for the whistling by the killer) and the use of silences and noise in the movie were highly innovative for the time and raised the dramatic function of sound to a new level (Marie 1989, 83). 
Thirdly, the two different mapping strategies not only refer to the two major notions of traditional cartography as discussed above, but also anticipate future cartographic developments. Before this cinemap, cartographic perspectives were usually either oblique or perpendicular. In this cinemap, both perspectives are juxtaposed, which predates the movement in virtual globes many years later. The capacity for changing perspectives interactively is a major feature of current virtual globes. This innovation was envisioned in this early cinemap, in which a change in perspective is also associated with a change in scale. The first circle representing the twokilometer radius is shot from the oblique perspective. It is only when the broader circle is drawn that the perspective changes. The oblique perspective is then associated with a local scale, while the vertical perspective is associated with coverage of a larger area.

Fourthly, this map is no longer about the journey, but about measurement and spatial analysis. The circles created with the compass symbolize the creation of what is called in GIS language "buffer zones." Even if we know that spatial measurement existed long before the appearance of GIS, this map suggests the early existence of analytical processes. The compass drawings also serve a narrative function. Through the construction of these buffers, the cinemap produces a different form of space. The authoritative voice and the absence of a human hand suggest that in fact the drawing is made by an institution - the police - instead of an individual. The space outlined by this institution expands inexorably and automatically through larger concentric circles. Berlin becomes the center of an expanding space controlled by the police. The fact that this control is still ongoing - the compass is still drawing - when the map dissolves, leaves the audience with the impression that these circles could expand indefinitely. In this sense, cinemaps can serve as a form of subtle narration of the expansion of control over territories.

While cinemaps appeared in movies in the first decade of the twentieth century, 1931 can be considered a turning point between classical and "modern" cartography as the cinemap in the movie $M$ conceptualizes many of the functions of contemporary digital cartography. Some additional functions such as zooming and the rendering of live data will appear in films in later decades.

\section{Post-1931: Technological developments in cinemaps Zooming capabilities}

The capability of zooming out from any point in the world to the entire globe in a few seconds - and vice-versa appeared in movies long before it became one of the more compelling functions of virtual globes. One of the earliest examples of the zooming technique can be found in Casablanca (Michael Curtiz, 1942). In the opening scene of the film, the audience is taken on what Tom Conley (2006: 84) calls a "desperate journey," from the entire world to the crowded streets of Casablanca through a succession of maps (see figure 3). The film opens with a spinning globe and a zoom-in shot towards Western Europe and France. The map fades into a larger-scale map of Europe centered on Paris, from which a bold line is drawn toward the South through Marseille, the Mediterranean Sea, Oran, and finally Casablanca, the setting for the film. At this point the map dissolves into a view from a high roof in the city, followed by a vertical panoramic (tilt shot) that takes the audience down to the busy streets of Casablanca. In one minute, we have crossed multiple scales from the entire globe to the street level.

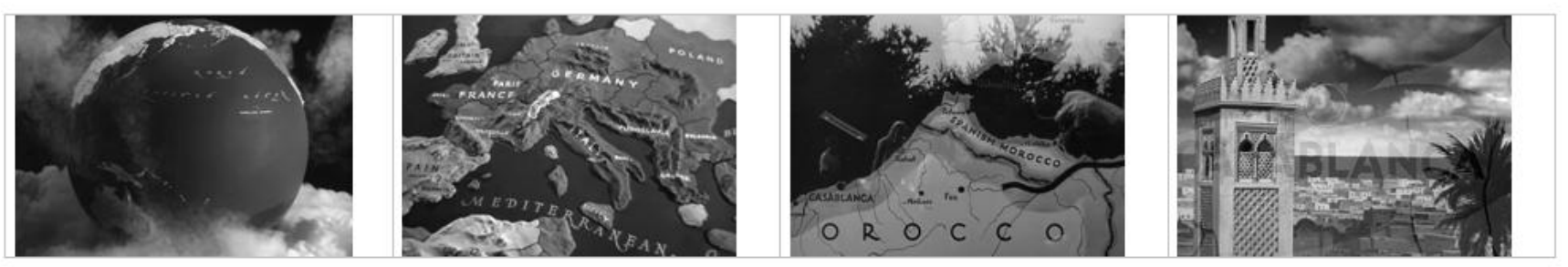

Figure 3 -From the global to the local through a series of larger scale maps: materialization of the zooming capabilities of virtual globes in the opening scene of Casablanca. 
This journey predates several of the zooming capabilities developed more than sixty years later in virtual globes. First, it integrates the combination of the spinning globe with a zoom effect on a specific point. Second, it uses a similar "jump" effect as the one currently available in Google Earth to move from one place to another. In this case, the journey from Paris to Casablanca starts with a zoom in on Paris, followed by a zoom out moving toward Southern Europe, then a zoom in to Morocco and finally Casablanca (see Figure 4). The jump effect is very compelling as it simultaneously follows the journey from Paris to Casablanca being traced on the map. Third, the perspective changes from ninety-degree view of the cartographic representation of the world, to an oblique perspective of the streets of Casablanca and resonates with the recent development of street views functionalities in applications such as Google Map (note: this functionality is not available yet for the city of Casablanca). This perspective change - or tilt - already suggested in $M$ with the two shots of the same map, is an integral part of this sequence. The opening sequence combines most of the zooming capabilities of current virtual globes, except for the smooth crossing of multiple images/maps which dissolve into each other in this cinemap.
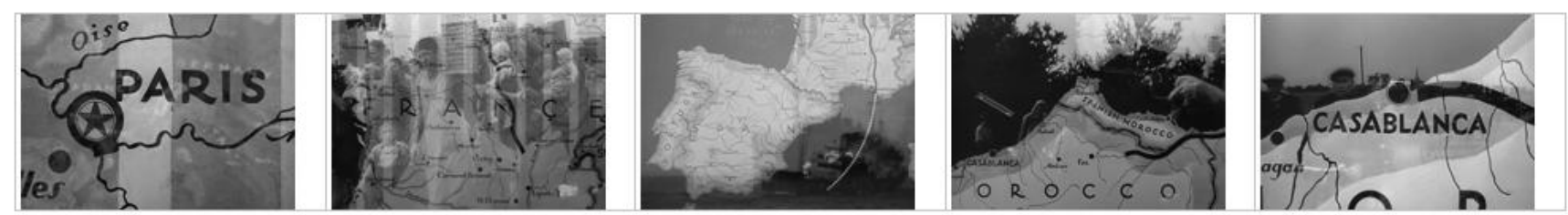

Figure 4-Zooming capabilities and "jump" effect from Paris to Casablanca in the opening scene of Casablanca.

It would be a few more decades before the production of satellite images and the development of computergenerated imagery could smooth the scale-crossing capabilities in movies. In 1977, Charles and Ray Eames began to combine these capabilities - with the support of IBM - to develop the didactic film, Powers of 10. This short film consists of a smooth and continuous zoom out from a couple in a park in Chicago, to the entire world and then to the limits of our universe (see Figure 5); followed by a zoom in back to the couple in the park, continuing on to one of their hands, to end up at the scale of a cell inside the body. Through this fascinating journey, Charles and Ray Eames resolve the issue of smooth zooming capabilities and complete the conceptualization started in Casablanca.
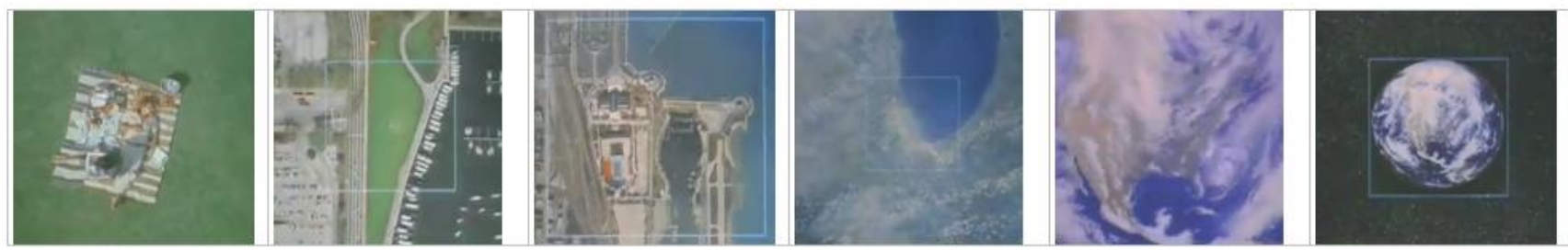

Figure 5 - In Powers of 10 smooth zooming effects are used to provide a journey from a human cell to the galaxy.

\section{Rendering Real-Time data}

With contemporary digital cartography, users have access in near real-time to geospatial information gathered by multiple sensors including satellites, video cameras, and radio frequency identification (RFID) tracking technologies. This access to live data through maps is another very important function of contemporary digital cartography that was not addressed in $M$, but in later movies as illustrated by two examples from 1964 .

In Dr. Strangelove, or How I Learned to Stop Worrying and Love the Bomb (Stanley Kubrick, 1964), which takes place during the cold war, a map with animated dots is used in the war room to represent the position of the US B52s sent - by mistake - to drop nuclear bombs on Soviet strategic targets. The map displays in "real time" the position of the planes. Dot by dot, the planes grow closer to their target, and to the ultimate destruction of the planet (see Figure 6). Fortunately, at the last minute, the US army is able to send the necessary code to call 
the planes back, avoiding a global nuclear war. The map contributes to the narrative as it depicts the movement of the planes. This real-time geospatial representation becomes the absolute reference of reality (Caquard and Taylor 2005). It also characterizes the emergence of the rendering of real-time geospatial data in our society as well as its importance for military horror and violence (Pickles 2004, 114).

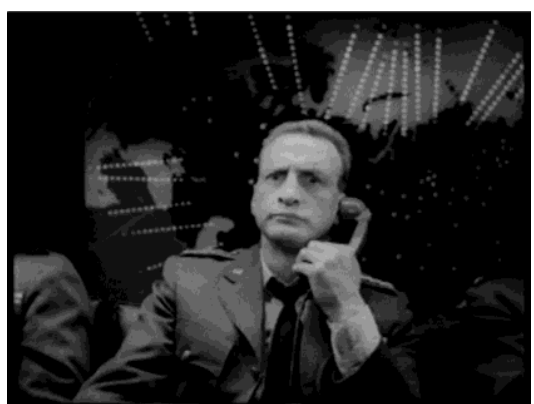

Figure 6. George C. Scott (aka General Turgidson) with the "big board" in the background showing in near real-time the position of the B52s flying toward their Soviet targets.

The very same year, a new James Bond movie - Goldfinger (Guy Hamilton 1964) - also included a map depicting real-time information. James Bond places a transmitter into the car of the villain, Goldfinger, who plans to use a nuclear bomb to irradiate the US federal gold reserve in order to stimulate a dramatic worldwide price increase of gold. With the transmitter, agent 007 is able to follow Goldfinger's car in real-time on a screen map in his Aston Martin through Europe and in the US (see Figure 7). In the context of the film, this map is associated with the bip-bip sound of a signal transmitter recording the different locations of Goldfinder's car. This map is used seven times during the movie and serves as an audio-visual leitmotiv, as well as a way to situate the audience in the different geographical settings of the action. This cinemap can vaguely, at least, be considered as a precursor of GPS navigating systems.

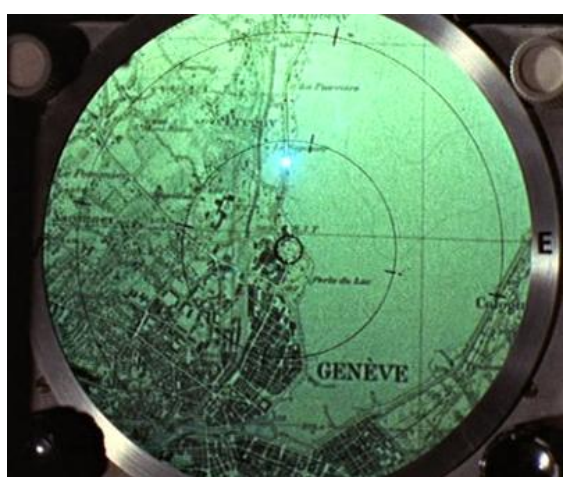

Figure 7. In Goldfinger, James Bond is able to follow the car of Goldfinger in real-time on a screen map in his Aston Martin through Switzerland. This cinemap might be considered as a precursor of GPS navigating system.

Both films, Dr. Strangelove and Goldfinger, deal with the nuclear threat of the cold war era. They envision the potential of geo-located live data in this context. In both examples the cinemap becomes part of the action which was not the case in previous examples. The cinemap is on the wall of the war room, and in James Bond's car. With these films, the cinemaps have moved from omniscient montage to the diegesis/action. While in the 1910s and 1920s cinemaps were added to clarify the action, in the 1960s they become part of the story just like any other traditional map hanging on the wall of a classroom or an office. In the 1960s, the technological map becomes part of the everyday material of military organizations and secret agents, predating the pervasiveness of the contemporary digital maps in our society, and in our daily life.

\section{Sketching the future of cartography through contemporary cinemaps}

Since early cinemaps predated contemporary cartographic practices, can we anticipate the future of cartography through the study of contemporary cinemaps? While it might be presumptuous to try to read the future of cartography, it might be interesting to emphasize some general trends in contemporary cinemaps in order to 
sketch some possible future directions for cartography. The pervasiveness of digital maps in our society is characterized by their massive presence in contemporary movies. Among this plethora of cinemaps three major types appear recurrently: (1) the jump-tilt effect maps that zoom in and out from the global to the local/personal; (2) the realistic fly-over terrains; and (3) the fantastic and magical maps.

As discussed previously both jump and tilt effects were already used in the early 1940s (see Casablanca in section 3). These effects have recently became popular in cartography through the use of virtual globes such as Google Earth. Virtual globes combine jump and tilt effects allowing the user to zoom in and out smoothly and instantaneously from the global to the local and vice-versa, and from the vertical view to the oblique view and vice-versa. This kind of effect has been used extensively in contemporary fiction films. For instance, in Stardust (Matthew Vaughn 2007) a cinemap with a tilt effect is used to take the audience from one place at one time - the Magical Kingdom of Stormhold in the $19^{\text {th }}$ century - to another place at another time - a near by village in England nine months later. The tilt effect here is combined with a nicely designed $19^{\text {th }}$ century map creating a smooth and elegant spatiotemporal transition between both scenes. What may be symptomatic of the future of cartography in this sequence from Stardust is that the jump-tilt effect takes the audience directly from the entrance door of a trailer to the entrance door of a house. In comparison to today virtual globes this cinemap gives us a higher level of detail and takes the audience right to the boundary of private space, bringing to the fore the increasing risk of the use of geospatial technologies to map and control our daily lives. Technological maps are not only becoming more widely used in the private sphere; our very personal activities are also becoming more and more systematically mapped and diffused. For instance, the movie Burn After Reading (Ethan and Joel Cohen 2008) starts with a long zoom that moves from a satellite view of North America to the interior of a FBI office in Washington DC where the action starts; and it ends with a zoom back from the very same office to the entire image of North America. This cinemap takes the audience directly form the global to the very specific environment of the office of the director of the CIA. While in Casablanca the jump-tilt was ending on the public space of a street, in Burn After Reading, the cinemap takes the audience through walls and roofs just like through layers of information and zooming back and forth from the global to the confitential and interpersonal level.

This trend can also be observed in the second recurrent type of contemporary cinemap: the fly-over terrains. For instance, in Stardust such a map is used to take the audience through a quick journey from the village - where the hero Tristan Thorne lives - to the palace of the king of Stormhold in a few seconds. This spatial connection reflects on the connections between the decisions made in the palace and their consequences on the life of the young man. This fly-over provides a way to connect spatially two different places. More interestingly, this flyover ends up inside the bedroom of the King after having entering the palace through its roof (see figure 8). Just like other fly-over surfaces, the example resembles flight simulators used by pilots for training, as well as flight simulation of self-guiding drone planes and precision guided missiles for military purposes (Pickles 2004, 156). Fly-over cinemaps resonate with the use of geographic technologies for military purposes. Just as in Burn After Reading, the high level of accuracy of this cinemap, as well as its incursion into the private sphere suggest that the potential future geotechnologies hold for warfare, as well as for any form of surveillance activity.
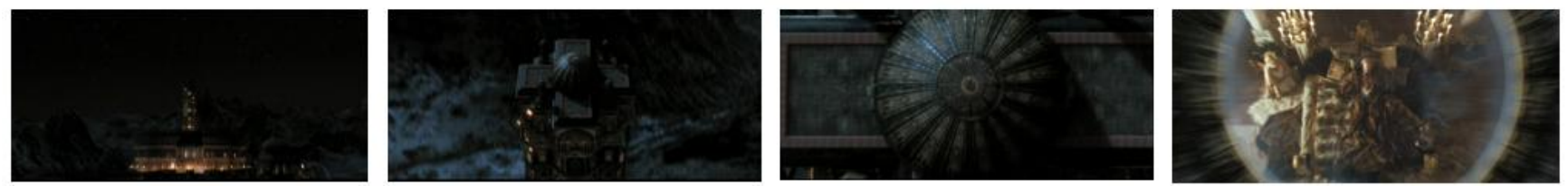

Figure 8. In Stardust, a fly-over cinemap ends up inside the private sphere of the bedroom of the King after having entering the palace through its roof.

The representation of our private activities through cinemap is also common in the third general category of contemporary cinemaps: the creation of maps of fantasy and magic. Among the different examples of these types of maps, one is of particular interest in the context of this paper: The Marauders Map from Harry Potter and the Prisoner of Azkaban (Alfredo Cuarón 2004). In this movie Harry Potter is given a magical map named the Marauders map (see figure 9). The power of this map lies in the fact that it shows "everyone, where they are, what they are doing, every minute of every day." This power resonates strongly with the military concept of 
Dominant Battlespace Awarness (DBA) which would allow a military force to "know where the enemy is, what it is doing, what it intends to do, and where its critical points are" (Corson and Palka 2004, 422). This military goal is also the ultimate goal of any form of surveillance project: knowing exactly who is where, and doing what at any time. With the capacity to map anyone's movement the Marauders map clearly embodies the surveillance potential of digital cartography. This map is the ultimate example of the power cartography might hold as a form of control and surveillance at the human scale and goes a step beyond the current mapping of moving objects such as planes, cars and cell phones, as well as the recording of our daily activities through video cameras.

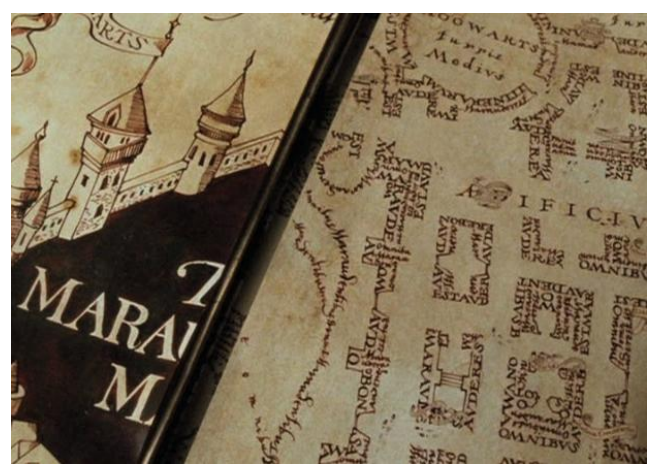

Figure 9. In Harry Potter and the Prisoner of Azkaban, the Marauders map shows "everyone, where they are, what they are doing, every minute of every day" resonating with the military concept of Dominant Battlespace Awarness (DBA).

Through these few examples it seems that contemporary cinemaps sketch cartographic futures that tend to penetrate more and more systematically interpersonal, confidential, and private spaces, while embodying some of the fantasies of geotechnology for military and control purposes. They offer an image of highly accurate and constantly updated information for the map users and to the audience. The potential technological maps hold for control and surveillance purposes has been discussed in cartography (see for instance Monmonier 2002; Pickles 2004). Yet, cinema had already anticipated this trend a long time ago, as illustrated by Tom Conley's analysis of Paris qui dort (René Clair 1925). Films and maps are both vehicles of control, and contemporary cinemaps may foreshadow the accumulation of surveillance technologies through up-to-date mapping of our private lives for example. Such a future reflects the ultimate goal of cartography as described by Lewis Caroll, Borges and other: developing a constantly updated map at a 1:1 scale. While this presents a somber perspective for future cartography there is still a ray of hope. Indeed in the three examples of contemporary cinemaps discussed in this section the audience is taken into a government office, a king's bedroom, as well as in the steps of the dark enemies of Harry Potter. In other words if these cinemaps enter more and more widely intimate or confidential spheres, such spheres are not just those of ordinary citizens, but also of those who wield power.

\section{Conclusion}

This paper argues that cinemaps have predated most of the functions and capabilities of contemporary digital maps, long before their development in cartography. While cinemaps have been a part of cinema since the 1910s, the one created in 1931 for $M$ can be seen foreshadowing a turning point between classical and "modern" cartography. This cinemap both refers to the classical dimensions of cartography, and predates several functions of contemporary digital cartography including the combination of realistic images and cartographic symbols, the use of sound, shifts in perspectives, spatial analysis, interactivity, and control over space. Other functions common in contemporary maps such as zooming effects and live data rendering appear in cinema in the 1940s, 1950s, and 1960s. Basically, when professional cartographers created their first animated maps, most of the functions of contemporary digital cartography had already been created and used in cinema.

This visionary dimension of cinema in respect to digital cartography leads to three concluding remarks. First, the cinematic expression of animated maps has not been given the importance it deserves. As illustrated in this paper, professional cartographers have a lot to learn from cinema in terms of techniques, concepts, combination of media, and narrative structure. Cinema has developed specific techniques and concepts for capturing and conveying complex spatiotemporal situations. It is therefore fundamental to explore more systematically and 
more deeply the potential influence cinema could have on cartography. Second, the time delay between the emergence of cinemaps in cinema and the emergence of similar functionality in digital cartography can be explained both by the visionary dimension of cinema, as well as by the multiple constraints related to mapmaking. Contemporary cartography is constrained by its functionalist and scientific dimensions to be accurate, panoptic and fully interactive. These constraints increase dramatically the complexity of the mapmaking process. Contemporary maps are user-orchestrated, they allow anybody to interact with them and to chose the representation, the area and the data they are interested in depending on its availability. Unlike cartography, cinema can show maps that do not have to work. Cinemaps are author-orchestrated, they must only look like they work. Third, as emphasized in the last section of this paper, cinema can serve as a conduit to future developments in cartography. Early cinemaps were able to illustrate many of the functions of current cartography; the study of the plethora of contemporary cinemaps might help us to sketch out the future of cartography, as well as to reflect on ethical and political dimensions of cartographic practices.

\section{Acknowledgements}

This research was supported by the Social Sciences and Humanities Research Council of Canada (SSHRC). I would also like to thank Benjamin Wright, Patricia Martin and Fraser Taylor for providing highly valuable editorial comments, as well as George R. Willeman and Conrad Froehlich for being so helpful in the quest of the very early cinemap from the Johnsons' movie.

\section{References:}

Beylie, C., (1997), Les films clés du cinéma, Larousse-Bordas, Paris.

Bruno, G., (1877), Le Tour de la France par deux enfants, Berlin, Paris.

Buache, F., (1984), Le Cinéma allemand, 1918-1933, Hatier, Paris.

Buci-Glucksmann, C., (1996), L'Oeil cartographique de l'art. Galilée, Paris.

Caquard, S. and Taylor, D. R. F., (2005), 'Art, Maps and Cybercartography - Stimulating Reflexivity among Map Users', in Cybercartography: Theory and Practice, ed. by Taylor, D.R.F., pp. 285-307, Elsevier, Amsterdam.

Castro, T., (2006), 'Les Archives de la Planète : a cinematographic atlas', Jump Cut. A Review of Contemporary Media, $\mathrm{n}^{\circ} 48$.

Clarke, D. and Doel, M. (2007), 'Shooting Space, tracking time: the city from animated photography to vernacular relativity', Cultural Geographies, 14, pp. 589-609.

Conley, T., (2006), Cartographic cinema, University of Minnesota Press, Minneapolis.

Coppock, J.T., (1988), The Analogue to Digital Revolution: A view From an Unreconstructed Geographer, The American Cartographer 15(3): 263-275.

Corson, M.W. and Palka, E.J., (2004), Geotechnology, The U.S. Military, and War, in Geography and Technology edited by Stanley D. Brunn, Susan L. Cutter, and JW Harrington Jr., Kluwer Academic Publishers, Dordrect.

Cosgrove, D., (1994), Contested Global Visions: One World, Whole Earth, and the Apollo space photographs, Annals of the Association of American Geographers 84 (2), pp. 270-294.

Crampton, J.W., (2003), The political Mapping of Cyberspace, University of Chicago Press, Chicago.

Eibel, A., (ed.) (1988), Lang (Fritz): Trois Lumières, Flammarion, Paris.

Foresman, T.W., (1998), The history of Geographic Information Systems, Prentice Hall.

Goodchild, M.F., (1988), 'Stepping over the line: technological constraints and the new cartography', American Cartographer, 15, pp. 311-319.

Harrower, M., (2004), 'A look at the history and future of animated maps', Cartographica, 39(3), pp. 33-42. 
Haraway, D., (1990), Primate Visions: Gender, Race, and Nature in the World of Modern Science, Routledge, New York.

Hayward, S., (2005), French National Cinema, Routledge, London and New-York.

Hébert, J. R. and Dempsey, P.E., (1997), 'Panoramic Maps of Cities in the United States and Canada', Online paper available at http://lcweb2.loc.gov/ammem/pmhtml/panintro.html (accessed May 2008).

Lange, E. and Bromberg, S., (2003), 'A la recherche du son', Audio visual documentary, Lobster Production, Paris.

Mark, M., Chrisman N., Frank A.U., McHaffie P.H., and Pickles J., (1996), 'The GIS History Project', http://www.geog.buffalo.edu/ncgia/gishist/bar harbor.html (accessed May 2008).

Marie, M., (1989), M le Maudit: Étude Critique, Nathan, Paris.

Monmonier M., (2002), Spying With Maps: Surveillance Technologies and the Future of Privacy, The University of Chicago Press, Chicago and London.

Pickles, J., (2004), A History of Spaces: cartographic reason, mapping and the geo-coded world, Routledge, London and New-York.

Saustier, A., (2006), 'Le Tour de la France par deux enfants', Web site, http://ecolepouilly.free.fr/tour2fr.htm (accessed May 2008).

Shohat, E. and Stam, R., (1994), Unthinking Eurocentrism: Multiculturalism and the Media, Routledge, London.

Speier, H., (1941), 'Magic Geography’, Social Research, 8(1/4), pp. 310-330.

Thrower, N., (1959), ‘Animated Cartography’, Professional Geographer, 11 (6), pp. 9-12.

Tobler, W., 1970, 'A Computer Movie Simulating Urban Growth in the Detroit Region', Economic Geography, 46, pp. 234-240.

Tomlinson, R.F., (1988), The Impact of the Transition From Analogue to Digital Cartographic Representation, The American Cartographer 15(3): 249-261. 